\title{
A CRIMINOLOGIA CRÍTICA DO SÉCULO XXI: A RELAÇÃO COM OS DIREITOS HUMANOS
}

\author{
Luana Rodrigues Meneses de Sá ${ }^{1}$ \\ Andréa Flores ${ }^{2}$
}

\begin{abstract}
Resumo:
O presente artigo versa sobre o escopo da criminologia crítica do século XXI. O problema consiste no questionamento do que deve ser prioritariamente defendido pela criminologia crítica no século XXI. O objetivo é investigar a relevância dos Direitos Humanos enquanto conteúdo da criminologia. Para tanto, utilizou-se da técnica de pesquisa bibliográfica, e o referencial teórico da criminologia crítica. As conclusões obtidas apontam que a Criminologia Crítica do século XXI deve redefinir-se no contexto da Criminologia dos Direitos Humanos, propondo a defesa prioritária do Direito Penal Mínimo como um direito humano.
\end{abstract}

Palavras-chave: Direitos Humanos; Criminologia Crítica; Criminologia dos Direitos Humanos; Direito Penal Mínimo; Política Criminal.

\section{THE CRITICAL CRIMINOLOGY OF THE 21ST CENTURY: THE RELATIONSHIP WITH HUMAN RIGHTS}

\begin{abstract}
:
This article discusses the scope of critical criminology in the 21st century. The problem is the questioning of what should be primarily defended by critical criminology in the 21 st century. The objective is to investigate the relevance of Human Rights as a content of criminology. For that, it used the technique of bibliographic research, and the theoretical framework of critical criminology. The conclusions obtained point out that the Critical Criminology of the $21 \mathrm{st}$ century must be redefined in the context of the Criminology of Human Rights, proposing the priority defense of the Minimum Criminal Law as a human right.
\end{abstract}

Keywords: Human Rights; Critical Criminology; Criminology of Human Rights; Minimum Criminal Law; Criminal Policy.

\section{Introdução}

No contexto das tendências regressionistas experimentadas pelas criminologias do século XXI, promovidas por movimentos de retrocessos nas teorias criminológicas, penais e políticas criminais fomentados desde o século XX, ocasião em que o "risco" passou a ocupar

\footnotetext{
${ }^{1}$ Mestranda em Direito pela Universidade Federal de Mato Grosso do Sul (UFMS). Advogada. E-mail: luanarodriguesmsa@gmail.com

${ }^{2}$ Doutora e Mestre em Direito pela PUC/SP. Professora do Programa de Mestrado em Direitos Humanos da Universidade Federal de Mato Grosso do Sul (UFMS). Professora da Graduação e da Pós-Graduação da UFMS e da UCDB. Professora da Escola Superior da Magistratura de Mato Grosso do Sul. Advogada. E-mail: andreaflores.adv@gmail.com
} 
o pensamento criminológico. Os modelos contemporâneos de justificação (vide teorias penológicas neoconservadoras, criminologia neokantiana, discursos da criminologia e política atuarial e funcionalista-sistêmico) da expansão penal são instrumentalizados para legitimar políticas regressivas, isto é, justificam uma contrarreforma institucional, onde ocorre a inversão dos princípios postulados pelos Direitos Humanos. Nessa conjuntura, convém ressaltar que a relevância da temática consiste na necessidade de se ter os Direitos Humanos como conteúdo da própria Criminologia, bem como destacar a proteção dos Direitos Humanos enquanto objeto e limite do poder punitivo estatal.

Com fundamento no referencial teórico da criminologia crítica, especialmente a partir da análise da produção científica da criminóloga Lola Aniyar de Castro e de Alessandro Baratta, pode-se observar reflexões e definições do que deve ser objeto de defesa prioritária e, consequentemente protegido institucional ou socialmente sob a perspectiva da criminologia crítica do século XXI.

O objetivo deste artigo é investigar, em apertada síntese, a relevância dos direitos humanos enquanto conteúdo da criminologia, indicando o objeto prioritário de defesa e de proteção institucional e social da criminologia crítica no século XXI. Portanto, o presente artigo delimitou-se a tratar do seguinte questionamento: o que deve ser prioritariamente defendido pela criminologia crítica no século XXI?

A Criminologia como Teoria Crítica do Controle Social, informal e formal, que no século XXI deve mudar a direção para a chamada Criminologia dos Direitos Humanos, além de passar por uma necessária renovação, realizar uma intersecção entre outros saberes (ampliar o estudo dos processos de criminalização fazendo a conexão com outras estruturas de poder, como o colonialismo e o racismo, o patriarcalismo, o sexismo, e especismo, entre outras), pois a referida Criminologia como Teoria Crítica do Controle Social, de base epistemológica da teoria crítica, é apta a exercer o controle dos controles (formal e informal), tendo os direitos humanos como objeto e limite da lei penal, pretendendo como objeto prioritário de defesa, proclamar o Direito Penal Mínimo como um direito humano.

Quanto à metodologia, investigou-se a produção acadêmica de Lola Aniyar de Castro e Alessandro Baratta, buscando pela palavra-chave: "Direitos Humanos". Assim, utilizou-se da técnica de pesquisa do tipo bibliográfica, interpretando-se à luz do referencial teórico da criminologia crítica.

O trabalho será dividido em três partes: a relação entre os direitos humanos e as 
criminologias, propostas para políticas penais vinculadas aos Direitos Humanos: o objeto prioritário de defesa e a Criminologia Crítica do século XXI: criminologia dos Direitos Humanos.

\section{A relação entre os Direitos Humanos e as Criminologias}

Não há uma criminologia, mas várias criminologias. Do mesmo modo, não há criminologia crítica no singular, mas várias criminologias críticas, vez que no sentido lato, as criminologias que não partiram do marxismo, mas sim do paradigma do "labeling approach" também adentram na seara do "criticismo" (termo estruturado por Vera de Andrade).

Definir o que é criminologia e qual criminologia aderir considera uma série de questões, como Lola Aniyar de Castro (2010b) defende, as diversas Criminologias existentes podem ser: Criminologia Clássica, Criminologia Biológica, Criminologia Positivista, Criminologia Prevencionista, Criminologia Funcionalista, Criminologia Organizacional, Criminologia Fenomenológica, Criminologia Socialista, Criminologia do Meio ambiente, AntiCriminologia, Criminologia Interacionista, Criminologia Dialética, Criminologia da Reação Social, Criminologia da Libertação, entre tantas outras e hoje, na era pós-crítica, há um empenho para se construir uma Criminologia dos Direitos humanos.

Zaffaroni (1988) escreve sobre o que ele chama de curso dos discursos da criminologia, onde o sentido é volátil. $O$ autor, numa tentativa de definição trata da Criminologia como uma análise crítica dos saberes, "não estritamente jurídicos", acerca da questão criminal, para a redução da violência a eles vinculados. A compreensão da dificuldade de definição perpassa pelo que Vera Malaguti (2012, p. 22- 23), afirma: “a criminologia como racionalidade positiva é uma resposta às necessidades de ordem que vão mudando no processo de acumulação do capital”.

Nesse sentido, o pensamento de Lola e Codino (2017, p 23) discorrem sobre a Criminologia ser um produto historicamente variável, da necessidade de manter uma Ordem Social. Entendimento que nos remete ao que Foucault (1987) escreve acerca do poder produzir o saber adequado à ordem e o saber reproduzir o poder e a ordem que o produziram.

A criminóloga Lola Aniyar de Castro (2017, p. 25, 29), não traça uma definição de 
Criminologia, mas indica requisitos para seguir o rastro do conhecimento criminológico, quais sejam, o primeiro trata-se de alguma definição do que deve ser objeto prioritário de defesa e, consequentemente, protegido institucional e socialmente; o segundo abrange os processos de criminalização com requisitos e limites; o terceiro aborda uma forma de controlar comportamentos socialmente negativos, considerados graves em determinado momento histórico e lugar. Além disso, um dos elementos necessários para narrar a história da criminologia é a observação de sua relação com os Direitos Humanos.

O estudo das obras de Lola Aniyar de Castro revela que a autora escreveu sobre Direitos Humanos e o que chama de "Criminologia dos Direitos Humanos", principalmente nos seguintes escritos: Manual de Criminologia Sociopolítica (edição brasileira publicada em 2017); Criminología de los Derechos Humanos: Criminología axiológica como política criminal (2010); e La criminología crítica en el siglo XXI como criminología de los derechos humanos y la contra-reforma humanística o las teorías criminológicas no son inocentes (2011).

Quanto à produção acadêmica de Alessandro Baratta, buscou-se priorizar a vinculação entre criminologia e direitos humanos, através da análise da sua obra que trata do Direito Penal Mínimo, que é ao mesmo tempo, o Direito Penal da Constituição.

O movimento pendular das criminologias historicamente ocorreu de uma extremidade a outra no que concerne ao vínculo com os direitos humanos, até chegar no ponto intermediário, que é capaz de tornar possível a comunicação entre os saberes, pois é a partir da criminologia crítica que as garantias e direitos passaram a figurar como características do pensamento criminológico crítico. $\mathrm{O}$ tensionamento central no estreitamento de laços dos saberes citados se encontra na controvérsia dos dois polos históricos dos direitos humanos: a igualdade e a liberdade, no que se refere ao controle social formal (especificamente o controle do crime), destaca-se nesse debate o conjunto de direitos dos mais vulneráveis (ANIYAR DE CASTRO, 2011, p. 15).

A pesquisa que explora a história em torno do estreitamento de laços das criminologias com os direitos humanos coopera para a adoção de uma visão ampla acerca da realidade social, agrega na investigação de como o substrato do pensamento criminológico pode legitimar ou deslegitimar medidas regressionistas (baseadas no eficientismo penal, na criação, perseguição e eliminação das garantias e direito de inimigos e nas políticas atuariais), contribuindo para ações ou omissões inseridas em determinados 
contextos, guiadas por diferentes demandas por ordem.

Lola Aniyar de Castro (2011) sustenta que as criminologias, de forma peculiar e não linear, seguem o movimento histórico dos Direitos Humanos proclamados pelas Nações Unidas, os da primeira dimensão (basicamente liberdade) se aproximam do que ela denomina de Criminologia Clássica (desenvolve os direitos humanos individuais); os direitos de segunda dimensão (fundamentalmente igualdade); os direitos da terceira dimensão (segundo a criminóloga, consta o direito ao meio ambiente, ao desenvolvimento, à nutrição, à informação).

No entanto, a vinculação com os direitos humanos se afasta com a Criminologia Positivista (paradigma etiológico), vez que a ênfase no conceito de periculosidade acarreta graves consequências para os direitos humanos, dado que as pessoas podem ser alvos do sistema penal apenas pela mera e suposta probabilidade de se converter em "delinquentes", os efeitos ideológicos são notáveis na dogmática (por exemplo, o direito penal do autor) e embasa um sistema penal, classista, racista e seletivo.

Com o advento da criminologia crítica nota-se a importância do direito de ser “diferente". A liberdade e igualdade, ou Justiça Social passam a nortear o discurso político, criminológico e penal por ser mais factível de judicialização, pois são direitos que guiam o enfrentamento do autoritarismo e seletividade do controle. A criminologia crítica em razão da sua observação permanente do exercício de poder e centrada na justiça social, concentrou seus esforços em ações pela democracia emancipatória, incorporou a concepção não só dos direitos comentados, mas de todos os direitos humanos para todas as pessoas. (ANIYAR DE CASTRO, 2011, pp. 16-17)

Aniyar de Castro e Codino (2017, p. 27), sustentam uma Criminologia como Teoria Crítica do Controle Social, considerando que os "Direitos Humanos são, atualmente, e por sua acolhida internacional, um guia estratégico e legitimado para a construção de uma contenção justa, dentro de uma sociedade justa para todos".

Para Machado e Pádua (2019, p.107) o entendimento de Lola acerca dos direitos humanos corresponde com a leitura de Herrera Flores (2009), porque ele afirma que os direitos humanos devem estar situados conforme a realidade social, composta por diferentes campos (econômico, jurídico e cultural, onde cada esfera contém uma junção de capitais simbólicos, institucionais, etc.) distribuídos desigualmente em função das relações fáticas de poder. 
Seguindo a lógica do termo "Criminologia dos Direitos Humanos", rapidamente cogita- se que o próximo passo seja a conversão da criminologia em um capítulo de uma ciência social dos Direitos Humanos, o que não é viável. Pensar em uma ciência social dos Direitos Humanos do mesmo modo que uma ciência total do Direito Penal de Von Liszt (no caso, uma ciência total dos Direitos Humanos), é o que Zaffaroni (2010b) considera um novo erro, porque todas as ciências, conservando suas respectivas identidades, devem orientar-se valorativamente para os Direitos Humanos. Portanto, a Criminologia, pode trabalhar para os Direitos Humanos, assim não correrá os riscos de fomentar, por ação ou omissão, novos e piores massacres.

Zaffaroni (2010b) ao escrever o prólogo do livro de Lola sobre a criminologia dos direitos humanos levanta dois questionamentos importantes, um sobre a dúvida se seria adequado falar em Criminologia dos Direitos Humanos ou Criminologia para os Direitos Humanos, a outra questão é quanto à provável compreensão de que escrever sobre a Criminologia dos Direitos Humanos pode ser uma aberração metodológica, pois surgirão perguntas como a seguinte: poderiam os cientistas virarem políticos? Quando a questão central a ser respondida trata-se da contradição do "dever ser" com a realidade, que não é teórica e nem acadêmica em solo latino-americano, faz parte da experiência do dia-a-dia. $\mathrm{O}$ autor alega que um dever ser que não pode chegar a ser não é direito, mas um disparate. Acrescenta-se o que Aniyar de Castro e Codino (2017, p. 383) escrevem: "Uma dogmática que estabelece um dever ser, mas que não é”.

A tradicional distinção presente nas ciências criminais (termo trabalhado por Von Liszt em consonância com pressupostos da criminologia positivista), em que o direito penal é eminentemente normativo e dogmático, ou seja, trata do "dever ser" e a criminologia é um saber empírico, se ocupando do "ser". Nessa questão, é possível perceber que o posicionamento de Lola Aniyar de Castro se coaduna com a crítica criminológica às teorias da pena feita por Salo de Carvalho (2020), o qual defende uma intencional violação à Lei de Hume (máxima lógica que discorre sobre a impossibilidade de intersecção dos saberes citados), dado que a criminologia crítica desconstruiu a referida lei. Aniyar de Castro explica:

A criminologia que chamamos de "crítica", acompanhando a tradição frankfurtiana, deve continuar em sua atitude demolidora e normativa (axiológica). Como foi dito, esta criminologia é um "dever ser". Desse modo, de um lado, embora o direito penal seja um "dever ser" da conduta, visto pelo enfoque da 
criminologia crítica ele se transforma em um ser, isto é, é analisado como o fato social que na verdade é. Embora pareça paradoxal, em razão de seus novos enfoques, a criminologia deve ser considerada como um "dever ser", enquanto o direito e o sistema penal em geral são o "ser" a estudar. (ANIYAR DE CASTRO, 2007, p. 199).

Do ponto de vista de Aniyar de Castro (2017, p. 29), "nossa criminologia é normativa (considerando não o que é, mas o que deve ser), da mesma maneira que o Direito Penal deve ser menos normativo e mais consciente da realidade". O que não é uma medida para aniquilar o Direito Penal, mas para preservar sua função garantidora e dotá-lo de novos conteúdos.

Nessa perspectiva, a questão da insuficiência do dogmatismo para lidar com a complexidade da realidade ocasionou uma demanda por um modelo atual e integrado das ciências criminais, caracterizado pela interdisciplinaridade externa, tendo a Criminologia equivalente à Política Criminal e ao Direito Penal, a qual deve fazer parte dos currículos dos cursos jurídicos, como uma forma de fazer uma ponte do direito penal com a realidade. (CALIL; NAPOLINI; RODRIGUES, 2020).

Baratta propôs um "novo modelo integrado", em que convergem a dogmática, a teoria e a Sociologia do Direito Penal, sob a perspectiva da Criminologia Crítica. Ao contrário do modelo positivista proposto por Liszt (1899), o ponto de vista criminológico deixa de ser interno, adota-se um ponto de vista externo ao sistema penal, distanciando-se de o papel auxiliar que a Criminologia Etiológica (positivista) ocupava. A interdisciplinaridade contribui para a construção do referido modelo, através de elementos da ciência do direito penal, utilizando elementos da teoria e da história social, da psicologia social, teoria da argumentação, entre outras. Os novos conteúdos do modelo analisam os processos sociais e institucionais de definição da criminalidade e da reação contra ela (BARATTA, 1998, p. 20 - 21).

Nesse sentido, Vera de Andrade (2012, p. 207) teceu críticas à dicotomia deve/ser, o dualismo encampado serve de recurso epistemológico e metodológico para recortar a realidade. Segundo a autora, o elo da interação da criminologia e dogmática pode ser identificado com o desenvolvimento do aspecto crítico da criminologia ao encontro do aspecto garantidor do direito penal dogmático.

\section{Propostas de políticas penais vinculadas aos Direitos Humanos: o objeto prioritário de defesa}


Para Lola Aniyar de Castro e Codino (2017), a Criminologia e a Política sempre andam juntas, normalmente um fio condutor externo é responsável pela ligação entre ambas. Segundo Baratta (1997) o conceito de Política Criminal é complexo, problemático e ideológico. Política Criminal enquanto gênero, detém um universo mais amplo do que a espécie política criminal.

A compreensão de que a orientação da política criminal deve seguir duas direções distintas e opostas, sendo orientada para a política de segurança ou para a política social é uma falsa alternativa, a diferenciação não é de ordem lógica, mas sim ideológica. Ao usar conceitos jurídicos rigorosos, tendo a segurança como a segurança dos direitos das pessoas físicas, a alternativa tende a desaparecer (BARATTA, 1997, p. 60).

Embora seja importante destacar a segurança dos direitos, não se ignora que parte da insegurança urbana decorre de comportamentos delituosos. Todavia, a necessidade de segurança dos cidadãos, não é apenas uma necessidade de proteção da criminalidade e dos processos de criminalização. A segurança dos cidadãos relaciona-se com a necessidade de estar e o sentimento de que possui a garantia de todos os direitos: direito à vida, à liberdade, ao livre desenvolvimento da personalidade e de suas próprias capacidades, direito de livre expressão e comunicação, direito à qualidade de vida, assim como o direito a controlar e influir sobre as condições da existência de cada um. (BARATTA, 1998, p. 41).

Importante destacar a diferença entre política penal e política criminal, a primeira é uma resposta à questão criminal adstrita ao âmbito do exercício da função punitiva do Estado (lei penal e sua aplicação, execução da pena e medida de segurança), e a segunda, compreende em sentido amplo, como política de transformação social e institucional. Uma política criminal alternativa é a que opta pela segunda opção, alternativa que é consciente dos limites do instrumento penal. (BARATTA, 2002, p. 201).

As principais propostas de políticas penais (espécie do gênero de políticas criminais) e outras perspectivas críticas oriundas da intersecção da Criminologia com os Direitos Humanos e discutidas pela criminóloga Lola Aniyar de Castro (2011), em resumo são as seguintes: a busca de um "referente material do delito" que permita a elaboração de incriminações que obedeçam ao interesse geral, através de uma teoria dos direitos humanos como objeto e limite da Lei Penal (Baratta); a proposta de criminalização prioritária de interesses difusos ou generalizáveis para todos (Sgubbi); a proposta de incriminar violações 
de direitos humanos reconhecidos pela Carta das Nações Unidas (Hermann e Julia Schwendinger inseridos na criminologia radical); e o realismo criminológico marginal e a Criminologia Cautelar (Zaffaroni).

A contribuição de Lola Aniyar de Castro (2017, p. 398) delimita as necessidades reais fundamentais sugeridas por Baratta como base para encontrar o referente material do delito, para tanto Lola foi buscar em aportes da antropologia, especificamente nos estudos acerca das comunidades estudadas por Malinowski (1970), em que ele se refere a uma tábua de necessidades básicas.

A criminóloga discute que o elemento para definir o referente material do Baratta, perpassa pelo reconhecimento de que o ser humano é portador de necessidades materiais (necessidades reais fundamentais), e que o Estado deve responder às necessidades básicas (comida, parentesco, abrigo, proteção, exercícios, atividades, higiene) protegendo os seguintes bens: vida, integridade, nutrição, estado civil, segurança física, liberdade espiritual e material, crescimento físico e espiritual, espaço, medicamentos e ambiente.

Os parâmetros para o referente material (Baratta) são os seguintes: o conceito de necessidades reais fundamentais, a representação dos interesses generalizáveis e que a defesa da emancipação dos setores mais frágeis, signifiquem a emancipação da sociedade geral. (ANIYAR DE CASTRO; CODINO, 2017, p. 361).

A teoria dos direitos humanos como objeto e limite da lei penal fornece a base teórica para definição do objeto de defesa prioritária e, consequentemente para aquilo que deve ser protegido institucional ou socialmente sob a perspectiva da criminologia crítica do século XXI, isto é, a discussão em torno da elaboração de incriminações que obedeçam ao interesse geral é o norte do espectro da criminologia crítica do século XXI.

Segundo a teoria citada, a proteção dos Direitos Humanos deve ser o objeto e concomitantemente, o limite do poder punitivo estatal, do mesmo modo que o objetivo a ser construído é um Direito Penal Mínimo (Direito Penal da Constituição ou Direito Penal Axiológico). A presente contrarreforma institucional vivenciada acarreta a inversão dos princípios postulados pelos Direitos Humanos. Dentre todos os princípios jus-humanistas, o que mais foi deixado de lado é o do Direito Penal Mínimo: o Direito Penal deixou de ser mínimo, como também deixou de ter a aparência formal do Direito Penal, em razão da sua “administrativização”. Estágio em que convém uma renovação da Criminologia Crítica para enfrentar o Estado policial-penal máximo e seu linguajar de guerra, para anunciar que o 
Direito Penal Mínimo deve ser considerado como um Direito Humano (ANIYAR DE CASTRO; CODINO, 2017, p. 468).

A articulação programática da ideia da mínima intervenção opera como guia para uma política penal a curto e médio prazo. A ideia é uma resposta aos requisitos mínimos de respeito dos direitos humanos na lei penal. O minimalismo penal como uma política criminal alternativa decorre da criminologia crítica e da teoria material dos direitos humanos.

Baratta (1987) dividiu os princípios do direito penal mínimo em dois grupos: os princípios intrassistemáticos e os princípios extrassistemáticos, os primeiros apontam requisitos para a introdução e a manutenção de figuras delitivas na lei penal, quais sejam, os princípios de limitação formal (princípios da reserva legal ou princípio da legalidade stricto sensu, princípio da taxatividade, princípio da irretroatividade, princípio do primado da lei penal substancial e princípio da representação popular); e os princípios de limitação funcional (princípio da resposta não contingente, princípio da proporcionalidade abstrata, princípio da idoneidade, princípio da subsidiariedade, princípio da proporcionalidade concreta, princípio da implementabilidade administrativa da lei penal, princípio do respeito às autonomias culturais e princípio do primado da vítima).

Em continuação, por último, os princípios de limitação pessoal ou de limitação da responsabilidade penal (princípio da imputação pessoal ou da personalidade, princípio da responsabilidade pelo fato e princípio da exigibilidade social). Já os princípios extrassistemáticos foram divididos em dois grupos: os princípios de descriminalização (princípio da não intervenção útil, princípio da privatização dos conflitos, princípios da politização dos conflitos e princípios da preservação das garantias formais); e os princípios metodológicos da construção alternativa dos conflitos e dos problemas sociais (princípio da subtração metodológica dos conceitos de criminalidade e de pena, princípio da não especificação dos conflitos e dos problemas, princípio geral de prevenção e princípio da articulação autônoma dos conflitos e das necessidades reais).

O Direito Penal Mínimo é, ao mesmo tempo, o Direito Penal da Constituição. Isto é, o espaço residual reservado à intervenção punitiva no marco da política integral de proteção dos direitos, quando a intervenção for indispensável para responder a graves violações de direitos fundamentais e atender uma demanda social necessária. Como direito penal da Constituição, os pressupostos do direito penal mínimo são: esforço contínuo da 
imaginação social para o controle do sistema punitivo e mecanismos de criminalização, uma reforma da legislação, justiça, polícia e prisão, concretização dos princípios constitucionais em matéria penal e a implementação dos resultados das mais avançadas investigações sobre o funcionamento dos sistemas penais e políticas públicas de proteção de direitos. (BARATTA, 1998, p. 94).

O Direito Penal da Constituição atualmente encontra-se na mesma condição que esteve outrora o direito penal do Iluminismo: ele deve limitar e regular a pena, mas para que o direito penal da Constituição não tenha a mesma sorte que o direito penal liberal, presente apenas na mente dos seus ideólogos, deve reencontrar uma dimensão política forte e autêntica. Isto somente será possível somente se incorporar uma política integral de proteção dos direitos fundamentais. (BARATTA, 1998, p. 39).

Nesse sentido, a chamada Criminologia dos Direitos Humanos, apta a exercer o controle dos controles, vigilante em atenção à observação fática do poder, será a mais adequada para discutir as problemáticas enfrentadas no século XXI, discorrendo acerca das referidas propostas vinculadas aos direitos humanos.

\section{A Criminologia Crítica do Século XXI: Criminologia dos Direitos Humanos}

Atualmente as tendências regressionistas estão inseridas no contexto de uma cultura de ódio, risco, medo e inimigo, abrem largas margens para violações de garantias e direitos fundamentais. Salo de Carvalho (2020, p. 132) assinala que os discursos criminológicos de dissuasão (cálculo racional), incapacitação (gerencialismo atuarial) e neutralização (funcionalismo-sistêmico), são responsáveis pela redução da ideia de controle social enquanto instrumento de segurança pública, assim a política criminal é encarregada de identificar riscos sociais e a pena torna-se uma ferramenta de neutralização e eliminação dos dissidentes (inimigos, excluídos e os outros).

Para obstaculizar a influência das tendências citadas, convém destacar o que Lola (2011) denota ser uma política criminal alternativa, que seja participativa, emancipatória, alternativa à prisão, não violenta, proclamada pelos oprimidos, ou seja, uma política criminal libertadora, descentralizada, plebiscitária, interdisciplinar e com garantia do direito à diferença, deste modo, os discursos criminológicos atrelados aos preceitos da criminologia atuarial (ligada ao terrorismo e ao fluxo transfronteiriço) perdem espaços e a 
visualização do imaginário social de caminhar sob um fio da navalha: de viver em uma sociedade atormentada por inimigos e riscos naturais e tecnológicos (vide sociedade de risco de Ulrich Beck), não importará na justificação da expansão penal. Nesse sentido:

\begin{abstract}
O século XXI, que foi oferecido cheio de progresso, solidariedade e humanismo, apresenta-se a nós na prática como um período de regressão e crise. Estamos diante do espetáculo constante de guerras, terrorismo, tribalismos e fundamentalismos, de violações em massa dos direitos humanos. Diante do comércio multimilionário e descontrolado de armas, e da guerra - que foi perdida - contra as drogas proibidas: uma derrota anunciada, aliás. E não menos importante, as exclusões de raças e países são reproduzidas como um muro protetor para o desenvolvimento econômico de unidades político-territoriais maiores, supostamente parte do processo de globalização, mas que, no entanto, possuem fronteiras culturais, fronteiriças e étnicas, que geram localismos violadores dos direitos humanos, que vão desde a redução ou eliminação do fluxo fronteiriço, até a repressão e, em seguida, à criminalização. (ANIYAR DE CASTRO, 2011, p. 575 - 576).
\end{abstract}

Nessa perspectiva o papel criminologia crítica assume novos contornos em atenção aos desdobramentos da globalização ocorridos no século XXI, a Criminologia Crítica parte do materialismo histórico e da Teoria Crítica da Escola de Frankfurt, o Controle Social sob o prisma crítico é destacado, ela também promove crítica cultural, e se vincula com os Direitos Humanos e as Garantias, pois enfoca-se politicamente e socialmente os aparelhos e operadores do Sistema Penal, o que marca o início da Criminologia dos Direitos Humanos. (ANIYAR DE CASTRO; CODINO, 2017, pp. 32-33). Portanto, a Criminologia como Teoria Crítica do Controle Social deve redefinir-se no contexto da Criminologia dos Direitos Humanos.

A epistemologia original da criminologia crítica é o interacionismo e o marxismo, a década em que é recepcionada é a de 70 do século XX, inicialmente nos Estados Unidos, a seguir na Europa chegando à América Latina. A criminologia Crítica cumpre o seu papel antipositivista, enfatizando os processos de criminalização, porém no século XXI urge sua renovação.

Vera de Andrade (2020), aponta que indicação epistemológica da Criminologia crítica de busca da totalidade e da conexão funcional entre estrutura social e pena continua válida e necessária para a Criminologia, mas, é insuficiente, vez que o capitalismo se mantém sendo a estrutura central, mas não esgota a totalidade estrutural que se busca para a compreensão da realidade brasileira, demandando, ser dotada de conhecimento de outras estruturas de poder, especialmente o colonialismo e o racismo, o patriarcalismo e o sexismo, e especismo e outras intersecções de saberes, que dialeticamente condicionam o controle social 
e penal.

A Criminologia Crítica ao ser normativa se converte em um dever ser. Um dever ser do Direito, especialmente, mas não é exclusivo, do Direito Penal. O Direito Penal, nessa relação mais entrelaçada que uma simbiose, se converte em um "ser". Esta é a razão se falar que a Criminologia Crítica e a Política Criminal são equivalentes. Trata-se de um evidente posicionamento antipositivista, visto que naquela época, a criminologia era o "ser", e o Direito Penal, o "dever ser". Ambos campos continuam sendo, mas sob a ótica crítica, de modo dialético. (ANIYAR DE CASTRO; CODINO, 2017, p. 351).

A Criminologia deixou de ser "Ciência Auxiliar do Direito Penal", o Direito tornou-se apenas um dos objetos de seu estudo e análise crítica. O Direito Penal, para esta nova Criminologia, faz parte do "ser" a ser estudado e observado, o "Ser" para o qual devese estar vigilante para controlar os desvios ocorridos no campo dos valores. Então, a Criminologia dos Direitos Humanos controla os controles. E, para realizar sua tarefa, precisa ter sob observação permanente os movimentos de todas as relações factuais de poder. (ANIYAR DE CASTRO, 2011, p.24).

No âmbito da Criminologia dos Direitos Humanos, a teoria crítica compõe o plano epistemológico, no nível criminológico consta a criminologia crítica, o nível interpretativo pousa sobre o Sistema de Justiça Penal, no nível político forma-se a Criminologia do Controle Social e dos Direitos Humanos, onde se defende (institucional e socialmente) como objeto prioritário, as medidas e penas alternativas, os direitos humanos como objeto e como limite da lei penal; a primazia da vítima; a participação social; o Direito Penal Mínimo; as necessidades reais fundamentais e os interesses emancipatórios e generalizáveis. (ANIYAR DE CASTRO; CODINO, 2017, p. 31, 33).

Aniyar de Castro (2010a, p. 375; 2017, p. 398, p. 402) elege Alessandro Baratta, o renomado criminólogo crítico como um criminólogo dos Direitos Humanos em razão da sua trajetória criminológica. Mesmo que Alessandro Baratta (1987) tenha reconhecido que o sistema penal não é o mais adequado para defender os Direitos Humanos, ele afirma que apenas violações dos direitos humanos fundamentais podem ser objeto de tutela penal. Deste modo, ele propõe o já citado Direito Penal Mínimo (resultado do seu diálogo com Ferrajoli), em que o seu conceito de direitos humanos, firmado na dupla função (mencionada no parágrafo seguinte), é tido como o fundamento apropriado para a estratégia da mínima intervenção penal e sua articulação programática inserida em uma política 
alternativa do controle social.

Segundo Baratta, o conceito (histórico-social) de direitos humanos ostenta uma dupla função. Em primeiro lugar, uma função negativa, relacionada aos limites da intervenção penal; em segundo lugar, uma função positiva ligada à delimitação do objeto possível, mas não necessário, da tutela penal. Ou seja, a violação de direitos humanos seria o núcleo "criminalizável” (ANIYAR DE CASTRO; CODINO, 2017, p. 402). Aniyar de Castro destaca a referida teoria dos direitos humanos como objeto e limite da lei penal:

Em resumo, os Direitos Humanos têm sido, pois, propostos como limite e como objeto do Direito Penal. Isto quer dizer que os Direitos Humanos são o limite da intervenção punitiva do Estado; e que o Direito Penal não está legitimado se não contribui para diminuir a violência punitiva. E, portanto, que os Direitos Humanos também são o limite e devem ser o conteúdo da própria Criminologia. (ANIYAR DE CASTRO; CODINO, 2017, p. 416).

Para ela, um criminólogo dos direitos humanos deve estar atento às tendências regressionista ocultas ou visíveis, que visam abolir a democracia construída com muito custo. O Direito Penal Mínimo (também chamado de Direito Penal Axiológico ou Direito Penal da Constituição) deve ser considerado um Direito Humano. A incoerência do duplo discurso das Constituições e dos Tratados Internacionais também devem ser enfrentadas, discurso que diz respeitar os Direitos Humanos, mas um sistema penal que não obedece a tais princípios.

De um lado, os organismos internacionais elencam cada vez mais bens protegíveis, e, por outro lado, os países signatários não estão dispostos a protegê-los, na prática, ou aqueles que ratificam são, na verdade, os maiores violadores de direitos, os que produzem mais vítimas. (ANIYAR DE CASTRO; CODINO, 2017, p. 362, 460).

Para Baratta (1997), “O programa de um direito penal mínimo, do direito penal da Constituição, não é somente o programa de um direito penal mais justo e eficaz; é também um grande desafio de justiça social e de pacificação dos conflitos".

A Criminologia dos Direitos Humanos, discute a proteção social e institucional da dos direitos humanos em atenção aos seguintes problemas: o panorama regional e internacional de guerras, migrações em massa, discriminações étnicas e ressurgimento de uma teoria criminal que exclui o "inimigo" das garantias - a urgência da promoção e reafirmação de um novo instrumento de análise orientado para os Direitos Humanos. (ANIYAR DE CASTRO, 2010, p. 33).

Para a autora (2011, p. 24), “[...] a Criminologia dos Direitos Humanos como 
Criminologia Crítica do Século XXI, será um compromisso com a vida, igualdade, liberdade, inclusão e segurança”. Ainda consoante Lola Aniyar de Castro (2010b, p. 296), “[...] não há igualdade, sem liberdade. Não há liberdade, sem igualdade”.

A criminologia que se pretende edificar será vigilante quanto ao suporte fático, observando os efeitos de uma Criminologia Atuarial (baseada em cálculos de probabilidade) e as das demais tendências regressionistas do século XXI, nesse sentido deve-se repensar o quanto a renúncia de direitos em detrimento de uma promessa frágil de segurança pode custar para a democracia, visto que não há liberdade, sem igualdade e que se faz necessário investigar os crimes em massa, os crimes de ódio, os discursos disfarçados de atribuição de direitos, os desvios dos organismos internacionais, assim como realizar o monitoramento da macrocriminalidade e das relações fáticas de poder.

Os direitos humanos, são considerados pela Criminologia Crítica como irrenunciáveis, e também indivisíveis; cabe retomar a ideia de que sem liberdade, não há igualdade. Esse equilíbrio, que só os trabalhadores políticos, sábios, mas humildes podem alcançar, é exatamente o desafio. (ANIYAR DE CASTRO, 2010, p. 296). Desafio posto diante das demandas por ordem que se apresentam no século XXI.

Lola Aniyar de Castro (2017, p. 416 - 417) adverte: "na prática, o controle formal se converte em um polvo de muitos braços, princípio institucional do controle social, que deixa reduzido, como nunca, o Direito Penal Convencional à sua mais limitada expressão simbólica”. Proclamar o Direito Penal Mínimo como um direito humano significará cortar os tentáculos do polvo, assim apenas as graves violações de direitos fundamentais serão objeto de tutela penal.

\section{Conclusão}

Com fundamento no referencial teórico da criminologia crítica, especialmente a partir da análise da produção científica da criminóloga crítica Lola Aniyar de Castro e de Alessandro Baratta, nota-se o estreitamento da relação entre Criminologia e Direitos Humanos, na perspectiva da criminologia crítica e com a finalidade de construir o Direito Penal Mínimo, sendo ao mesmo tempo, o Direito Penal da Constituição.

$\mathrm{O}$ que deve ser prioritariamente defendido pela criminologia crítica no século XXI são os interesses emancipatórios e generalizáveis, as necessidades reais fundamentais, e que a 
defesa da emancipação dos setores mais vulneráveis, impliquem na emancipação da sociedade geral, a primazia da vítima, a participação social, a proclamação do Direito Penal Mínimo como um direito humano, para que as graves violações de direitos fundamentais sejam objeto de tutela penal quando for inevitável.

Nesse sentido, a contribuição da teoria dos Direitos Humanos como objeto e limite da lei penal é importante para fornecer elementos para a elaboração de um referente material do delito, ou seja, para a definição dos interesses ou necessidades, os citados requisitos mínimos do objeto de tutela penal. Assim, os direitos humanos conduzem a estratégia mais adequada para a elaboração dos princípios minimalistas inseridos em uma política criminal alternativa.

No cenário de tendências regressionistas nas criminologias, vislumbra-se na Criminologia Crítica do século XXI a conversão para a Criminologia dos Direitos Humanos, com a necessária renovação e intersecção com outros saberes (ampliar o estudo dos processos de criminalização fazendo a conexão com outras estruturas de poder, como o colonialismo e o racismo, o patriarcalismo, o sexismo, e especismo, entre outras), sendo uma criminologia do controle social, firmada sob a base epistemológica da teoria crítica, apta a exercer o controle dos controles (formal e informal), observar os desvios dos organismos internacionais e as relações fáticas de poder, a criminalidade macro, os crimes em massa e os crimes de ódio e promover a articulação de uma política integral de proteção dos direitos fundamentais.

\section{Referências}

ANDRADE, Vera Regina Pereira de. Criminologia em pedaços: manifesto por uma aliança para a brasilidade. Boletim IBCCRIM, São Paulo, v. 28, n. 328, p. 23-26, mar. 2020. Disponível em: https://www.ibccrim.org.br/publicacoes/edicoes/36/245. Acesso em: 15 mar. 2021.

ANDRADE, Vera Regina Pereira de. Pelas mãos da Criminologia: o controle penal para além da (des)ilusão. Rio de Janeiro: Revan, 2012.

ANIYAR DE CASTRO, Lola. A evolução da teoria criminológica e avaliação de seu estado atual. Revista de Direito Penal. Rio de Janeiro, n. 34, p. 71-92, 1982. Disponível em: http://200.205.38.50/biblioteca/index.asp?codigo_sophia=20709. Acesso em: 3 abr. 2021.

ANIYAR DE CASTRO, Lola. Baratta y La Criminología Crítica un Filósofo que Revolucionó la Criminología y la Encaminó a ser Teoría Crítica del Control Social.

Revista Digital de la Maestría en Ciencias Penales, n. 2, p. 367-367, 2010a. 
ANIYAR DE CASTRO, Lola. Criminología de los Derechos Humanos:

Criminología axiológica como política criminal. Prólogo de Eugenio Raúl Zaffaroni. Buenos Aires, Argentina: Editores del Puerto, 2010b.

ANIYAR DE CASTRO, Lola Aniyar. Criminologia da libertação. Rio de Janeiro: Revan: ICC, 2005.

ANIYAR DE CASTRO, Lola. Direitos humanos: delinquentes e vítimas, todos vítimas. Tradução de Sylvia Moretzsohn. Discursos Sediciosos: crime, direito e sociedade, Rio de Janeiro, 15/16, p. 187-202, anual. 2007. Disponível em:

http://200.205.38.50/biblioteca/index.asp?codigo_sophia=65357. Acesso em: 31 ago. 2020.

ANIYAR DE CASTRO, Lola. La Criminología Crítica en el siglo XXI como criminología de los derechos humanos y la contra-reforma humanística o las teorías criminológicas no son inocentes. Revista Interferencia, 2011. Disponível em:

https://rdu.unc.edu.ar/handle/11086/6118. Acesso em: 20 dez. 2020.

ANIYAR DE CASTRO, Lola. La criminología hoy: política criminal como síntesis de la criminología: política penal y relaciones con la teoría de la responsabilidad: un control social alternativo o la criminología de los derechos humanos. Revista Brasileira de Ciências Criminais, São Paulo, v. 8, n. 32, p. 252-268, 2000. Disponível em: http://200.205.38.50/biblioteca/index.asp?codigo_sophia=31469. Acesso em: 15 dez. 2020.

ANIYAR DE CASTRO, Lola. La nueva criminología y los derechos humanos. Revista Chilena de Derechos Humanos, 1986, n.5. Disponível em: http://bibliotecadigital.academia cl/handle/123456789/3789. Acesso em: 10 abr. 2021.

ANIYAR DE CASTRO, Lola; CODINO; Rodrigo. Manual de Criminologia Sociopolítica. Trad. Amina Vergara. Rio de Janeiro: Revan, 2017.

BARATTA, Alessandro. Criminologia Crítica e Crítica do Direito Penal: Introdução à Sociologia do Direito Penal. 3a ed. Trad. Juarez Cirino dos Santos. Rio de Janeiro: Revan, 2002.

BARATTA, Alessandro. Defesa dos direitos humanos e política criminal. Discursos Sediciosos: crime, direito e sociedade, Rio de Janeiro, v. 2, n. 3, p. 57-69, 1997. Disponível em: http://200.205.38.50/biblioteca/index.asp?codigo_sophia=21104. Acesso em: 13 abr. 2021.

BARATTA, Alessandro. Direitos humanos: entre a violência estrutural e a violência penal. Fascículos de Ciências Penais, Porto Alegre, v. 6, n. 2, p. 44-61,v1993. Disponível em:https://edisciplinas.usp.br/pluginfile.php/5571686/mod_folder/content/0/ALESSANDR O\%20BARATA.pdf?forcedownload=1. Acesso em: 13 fev. 2021.

BARATTA, Alessandro. La política criminal y el derecho penal de la constitución: nuevas reflexiones sobre el modelo integrado de las ciencias penales. Revista de Ciencias 
Penales: Montevideo, Montevideo, v. 4, p. 75-100, 1998. Disponível em: http://200.205.38.50/biblioteca/index.asp?codigo_sophia=121192. Acesso em: 14 abr. 2021.

BARATTA, Alessandro. Princípios do direito penal mínimo: por uma teoria dos direitos humanos como objeto e limite da lei penal. Revista Doutrina Penal, n. 10-40, Buenos Aires, Argentina: Depalma, 1987. pp. 623-650.

BATISTA, Vera Malaguti. Introdução crítica à criminologia brasileira. $2^{\mathrm{a}}$ ed. Rio de Janeiro: Revan, 2012.

BECK, Ulrich. La sociedade del riesgo: hacia una nueva modernidad. Barcelona: Paidós, 1998.

CALIL, Mário Lúcio Garcez; NASPOLINI, Samyra Haydêe Dal Farra; RODRIGUES, Horácio Wanderlei. Ensinar criminologia: entre Von Liszt e Baratta. Revista de Direito Brasileira, v. 26, n. 10, p. 471-483, 2020.

CARVALHO, Salo de. Penas e Medidas de Segurança no Direito Brasileiro. São Paulo: Saraiva, 2020.

FOUCAULT, Michel. Vigiar e punir: história da violência nas prisões. Tradução de Ligia M. Pondé Vassalo. Petrópolis: Vozes, 1987.

HERRERA FLORES, Joaquín. A (re) invenção dos direitos humanos.

Florianópolis: Fundação Boiteux, 2009.

MACHADO, Bruno AMARAL; PÁDUA, Thiago AGUIAR DE. Reminiscências do pensamento crítico de Lola Aniyar de Castro e o julgamento dos crimes contra a humanidade no Brasil. Utopía y Praxis Latinoamericana, v. 24, p. 100-122, 5 set. 2019.

SÁ, Luana Rodrigues Meneses; FLORES, Andréa. A criminologia dos direitos humanos à luz do pensamento criminológico crítico de Lola Aniyar de Castro. In: VIII Congresso Nacional da FEPODI, 2021, São Paulo. Anais eletrônicos. Universalização do conhecimento e democratização da pesquisa. São Paulo: Fepodi, 2021, p. 106-116.

VON LISZT, Franz. Tratado de Direito Penal Alemão. Tomo I. Rio de Janeiro: F. BRIGUIET \& C, 1899.

ZAFFARONI, Raúl Eugenio. Criminología. Aproximación desde un margen. Bogotá: Temis, 1988. 